\title{
$\mathrm{X}$ \\ CORRESPONDENCE
}

To the Editors, The British Journal of Venereal Diseases.

September 23rd, I936.

\section{Recent Research in Connection with Venereal Disease}

DEAR SIRS,--I have read with much pleasure and interest the excellent paper which Dr. Osmond read before the Society for the Study of Venereal Disease in April last, and much regret that I was unable to be present at the meeting.

It is true that Dr. Osmond states at the end of his paper that he makes no pretence to comprehensiveness or to cover all the ground, but inasmuch as he refers to the treatment of vulvo-vaginitis and states that it is so unsatisfactory " that the successful use of ovarian follicular hormone given in vaginal gelatine suppositories reported by Witherspoon is at least encouraging," it is somewhat surprising that he makes no reference to the treatment of this condition in little girls with œstrin, either by injection or by mouth. The method was originally reported upon by $\mathrm{R}$. M. Lewis, of Newhaven, Connecticut, in the American Journal of Obstetrics and Gynacology in I933, who reports eight cases in which the treatment was used with marked success. Subsequently, the method was introduced into the Clinic at the Hospital for Sick Children, Great Ormond Street, and in March, I935, I reported, in conjunction with my colleague, Dr. A. Gordon Signy, a series of twenty cases in which the treatment had been applied and found very valuable. Since then I have used no other treatment except local irrigations, and I am convinced that the oral administration of œestrin is a very distinct advance in the treatment of juvenile vulvo-vaginitis.

I believe some V.D. clinicians who have tried it have not been equally successful. It may be that the preparation used by them was not the same, but I may add that all our investigations have been carried out with "Menformon" as supplied by the Organon Laboratories.

I am,

Yours faithfully,

David Nabarro. 